\title{
Erratum to: Microstructure and non-isothermal crystallization behavior of PP/PLA/clay hybrid nanocomposites
}

\author{
Hassan Ebadi-Dehaghani ${ }^{1}$ - Mehdi Barikani ${ }^{1} \cdot$ Hossein Ali Khonakdar ${ }^{1,2}$. \\ Seyed Hassan Jafari ${ }^{3}$
}

Received: 8 May 2015/Accepted: 9 May 2015/Published online: 4 June 2015

(C) Akadémiai Kiadó, Budapest, Hungary 2015

\section{Erratum to: J Therm Anal Calorim DOI 10.1007/s10973-015-4554-8}

The correct name is:

Mehdi Barikani instead of Mahdi Barikani
His correct affiliation is:

Iran Polymer and Petrochemical Institute, P.O. Box 14965/115, Tehran, Iran instead of Leibniz Institute of Polymer Research Dresden, D-01067, Dresden, Germany

The online version of the original article can be found under doi: 10.1007/s10973-015-4554-8.

Hossein Ali Khonakdar

hakhonakdar@gmail.com

Hassan Ebadi-Dehaghani

ebadi@iaush.ac.ir

1 Iran Polymer and Petrochemical Institute, P.O. Box 14965/115, Tehran, Iran

2 Leibniz Institute of Polymer Research Dresden, 01067 Dresden, Germany

3 School of Chemical Engineering, College of Engineering, University of Tehran, P.O. Box 11155-4563, Tehran, Iran 